Article

\title{
Evaluation of Remote Sensing Inversion Error for the Above-Ground Biomass of Alpine Meadow Grassland Based on Multi-Source Satellite Data
}

\author{
Baoping Meng ${ }^{1}$, Jing Ge ${ }^{1}$, Tiangang Liang ${ }^{1, *}$, Shuxia Yang ${ }^{1}$, Jinglong Gao ${ }^{1}$, Qisheng Feng ${ }^{1}$, \\ Xia Cui ${ }^{2}$, Xiaodong Huang ${ }^{1}$ and Hongjie $\mathrm{Xie}^{3}$ \\ 1 State Key Laboratory of Grassland Agro-ecosystems, College of Pastoral Agriculture Science and \\ Technology, Lanzhou University, Lanzhou 730020, China; mengbp09@1zu.edu.cn (B.M.); \\ gej12@lzu.edu.cn (J.G.); yangshx2014@lzu.edu.cn (S.Y.); rslabjinlong@163.com (J.G.); \\ fengqsh@lzu.edu.cn (Q.F.); huangxd@lzu.edu.cn (X.H.) \\ 2 Key Laboratory of Western China's Environmental Systems (Ministry of Education), College of Earth and \\ Environmental Sciences, Lanzhou University, Lanzhou 730000, China; xiacui@lzu.edu.cn \\ 3 Laboratory for Remote Sensing and Geoinformatics, University of Texas at San Antonio, San Antonio, \\ TX 78249, USA; hongjie.xie@utsa.edu \\ * Correspondence: tgliang@lzu.edu.cn; Tel.: +86-931-981-5306; Fax: +86-931-891-0979
}

Academic Editors: Lalit Kumar, Onisimo Mutanga, Lars T. Waser and Prasad S. Thenkabail Received: 21 January 2017; Accepted: 13 April 2017; Published: 16 April 2017

\begin{abstract}
It is not yet clear whether there is any difference in using remote sensing data of different spatial resolutions and filtering methods to improve the above-ground biomass (AGB) estimation accuracy of alpine meadow grassland. In this study, field measurements of AGB and spectral data at Sangke Town, Gansu Province, China, in three years (2013-2015) are combined to construct AGB estimation models of alpine meadow grassland based on these different remotely-sensed NDVI data: MODIS, HJ-1B CCD of China and Landsat 8 OLI (denoted as NDVI $_{\mathrm{MOD}}$, NDVI $\mathrm{NCD}_{\mathrm{C}}$ and $\mathrm{NDVI}_{\mathrm{OLI}}$, respectively). This study aims to investigate the estimation errors of AGB from the three satellite sensors, to examine the influence of different filtering methods on MODIS NDVI for the estimation accuracy of AGB and to evaluate the feasibility of large-scale models applied to a small area. The results showed that: (1) filtering the MODIS NDVI using the Savitzky-Golay (SG), logistic and Gaussian approaches can reduce the AGB estimation error; in particular, the SG method performs the best, with the smallest errors at both the sample plot scale $(250 \mathrm{~m} \times 250 \mathrm{~m})$ and the entire study area (33.9\% and $34.9 \%$, respectively); (2) the optimum estimation model of grassland AGB in the study area is the exponential model based on $\mathrm{NDVI}_{\mathrm{OLI}}$, with estimation errors of $29.1 \%$ and $30.7 \%$ at the sample plot and the study area scales, respectively; and (3) the estimation errors of grassland AGB models previously constructed at different spatial scales (the Tibetan Plateau, Gannan Prefecture and Xiahe County) are higher than those directly constructed based on the small area of this study by $11.9 \%-36.4 \%$ and $5.3 \%-29.6 \%$ at the sample plot and study area scales, respectively. This study presents an improved monitoring algorithm of alpine natural grassland AGB estimation and provides a clear direction for future improvement of the grassland AGB estimation and grassland productivity from remote sensing technology.
\end{abstract}

Keywords: alpine meadow grassland; above-ground biomass; inversion model; error analysis; applicability evaluation

\section{Introduction}

As the largest terrestrial biome on the Earth's surface [1], the grassland biome occupies approximately $40 \%$ of the total land area [2], and its net primary productivity accounts for approximately $20 \%$ of 
the production capability of the entire land biome [3]. In China, the grassland biome accounts for approximately $1 / 3$ of the total national territory. Grasslands play a critical role not only in animal husbandry, but also in energy exchange, carbon sequestration and the biogeochemical cycle. In particular, the effect of the grassland biome is more prominent in the vast central and western regions of China $[4,5]$.

Grassland vegetation is defined as permanent vegetation composed of an herbaceous plant community [2]; the above-ground biomass (AGB) of grassland provides the basis for estimating the net primary productivity of grassland [6]. Overall, AGB can be used to directly estimate grassland productivity $[7,8]$. In general, AGB is defined as the weight of dry grass in the above-ground portion within one unit area [9]. Monitoring using remote sensing data is the most effective method for collecting continuous spatial and temporal data on the regional or global scale $[10,11]$, because satellite remote sensing can provide large-scale, frequent, low cost and massive information [12]. Therefore, it has gradually replaced traditional methods of ground biomass monitoring, which are inefficient and expensive. Since NDVI was first applied to study natural grasslands in the 1970s, research on the linkage between vegetation indices and AGB has had a history extending over several decades [13-17]. Because grassland AGB estimations can directly guide livestock production, evaluating the accuracy of estimation models is highly important. Numerous studies have indicated that factors such as the representativeness of ground sampling sites, the temporal and spatial resolutions of satellite images, the types of sensors and the methods of remote sensing image processing [18] are responsible for the large differences between the grassland AGB models developed by different scholars even for the same region or the same type of grassland. These differences exist not only in the form of the models, but also in the estimation errors. At present, grassland AGB estimation is often based on the statistical models on a specific remote sensing vegetation index [19-22]. For alpine meadow grassland, which type of remote sensing estimation model is the most suitable is currently unknown. Existing studies indicate that using both high spatial resolution imagery and filtering the vegetation index can increase the accuracy of grassland AGB estimation [18,23-25]. However, it is not yet clear whether there is any difference in using remote sensing data of different spatial resolutions and filtering methods to improve the AGB estimation accuracy of alpine meadow grassland. Therefore, further comparisons and studies must be conducted.

In this study, considering the factors discussed above, a region of alpine meadow grassland in the Tibetan Plateau area is used to perform the following investigations: (1) by comparing and analyzing the AGB estimation models and their accuracies based on the NDVI of multi-source remote sensing data, the influences of different remote sensing data and filtering methods on the error of grassland AGB estimation are revealed; (2) the data from the sample plots observed inside the study area are used to validate the applicability of previous grassland models based on MODIS data and to investigate the reasons for errors from different models; and (3) based on the above research results, we propose a method to improve the accuracy of grassland AGB estimation.

\section{Data and Methods}

\subsection{Study $A=\pi r^{2}$}

The study area $\left(102^{\circ} 23^{\prime}-102^{\circ} 26^{\prime} \mathrm{E}, 35^{\circ} 5^{\prime}-35^{\circ} 7^{\prime} \mathrm{N}\right)$ is located in the Yangji Community of Sangke Town in Xiahe County, Gansu Province, with a size of approximately $3.86 \mathrm{~km}(\mathrm{~N}-\mathrm{S}) \times 2.77 \mathrm{~km}(\mathrm{E}-\mathrm{W})$ and a mean elevation of $3050 \mathrm{~m}$ (Figure 1). The natural grassland type in the study area is alpine meadow. The dominant pasture plants include alpine Kobresia pygmaea C B Clarke, Elymus nutans Griseb, Festuca ovina L, Poa annua L, Koeleria litwinowii Domin var and Astragalus membranaceus Bunge, while the primary malignant weeds include Ligularia virgaurea Mattf, Leontopodium japonicum, Potentilla chinensis Ser and Pedicularis resupinata L. The dominant grazing livestock are yak and Ganjia sheep. The study area is cold and wet throughout the year, and it belongs to the continental monsoon climate of the temperate plateau. The annual average temperature is $2.1^{\circ} \mathrm{C}$; the annual average rainfall is $580 \mathrm{~mm}$. 

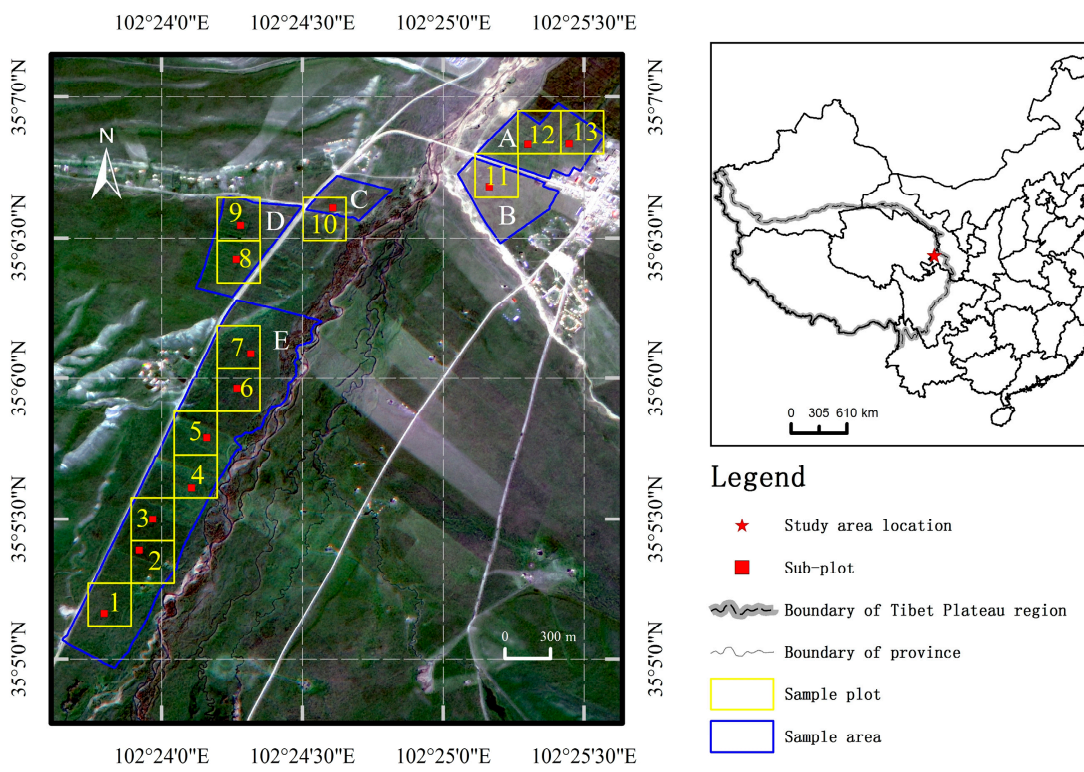

Figure 1. Distributions of experimental sample areas (A-E), with sample plots (yellow squares) and sub-plots (red small squares with their identification numbers as yellow), in Xiahe County, Gansu Province. Each sample area has a similar situation of grass growth; each sample plot is a MODIS pixel of $250 \mathrm{~m} \times 250 \mathrm{~m}$; each sub-plot is a $30 \mathrm{~m} \times 30 \mathrm{~m}$ plot with five sample quadrats (see the details in Section 2.2).

The study area consists of five fenced experimental sample areas (A-E) of natural alpine meadow grassland (Figure 1), with a total area of 161.36 ha. Specifically, Area A (19.38 ha) was used to conduct natural grassland reseeding tests; Area B (16.06 ha) was used for grazing utilization experiments; Area C (7.52 ha) acted as a non-treatment testing control area; Area D (19.30 ha) was an experimental area for grassland enclosure; and Area E ( 99.10 ha, accounting for $61.55 \%$ of the total experimental area) was used for artificial fertilization experiments. The grassland growth in these five experimental areas differed because of the above different usages.

\subsection{Sampling Strategy and Data Collection}

A total of 13 sample plots of $250 \mathrm{~m} \times 250 \mathrm{~m}$ were set up inside the five experimental sample areas. In each sample plot, a $30 \mathrm{~m} \times 30 \mathrm{~m}$ sub-plot was set up for data collection. In each sub-plot, five quadrats $(1.5 \mathrm{~m} \times 1.5 \mathrm{~m}$ each) were set up as shown in Figure 2, taking the central point and the four corner points to represent the entire sub-plot. To reduce the artificial sampling error of biomass measurements, a strategy of 9 sub-quadrats was also used for avoiding repeat sampling in each year (Figure 2). The locations of the 13 sample plots were selected based on the following factors: (1) the growth status of the grassland was relatively uniform and was spatially representative; and (2) each sample plot $(250 \mathrm{~m} \times 250 \mathrm{~m})$ corresponded to one MODIS pixel. However, in each sample plot, the sub-plot of $30 \mathrm{~m} \times 30 \mathrm{~m}$ was randomly selected, corresponding to a Landsat 8 OLI and HJ-1B CCD pixel.

During the grassland growth seasons from 2013 to 2015, observations were performed approximately every $10 \mathrm{~d}$, and a total of 20 field investigations was conducted over the three years. Due to factors such as weather conditions and satellite image time phases, only five times of field measurement data were matched well with satellites and were selected. They were August 2013, July 2014 and July, August and October 2015; with a total of 325 quadrat observations (see the details in Section 2.4) used to construct and analyze the biomass model. 


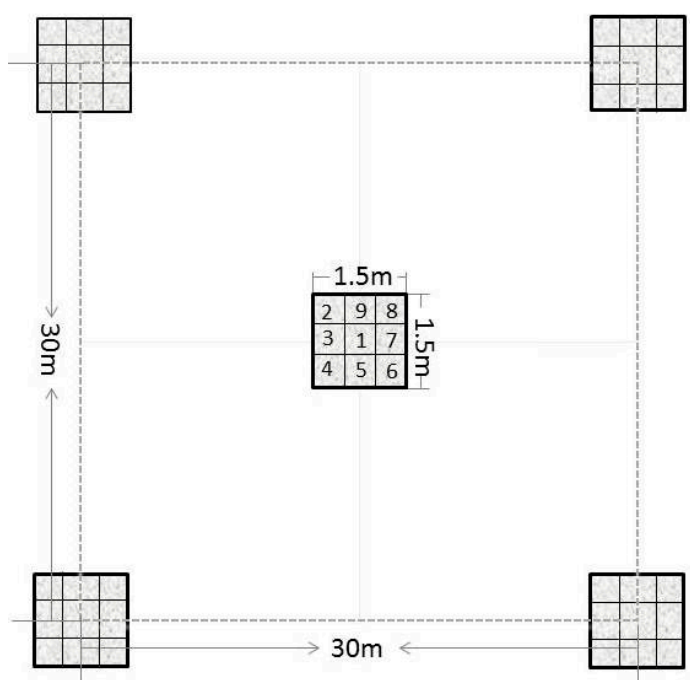

Figure 2. Distributions of the five quadrats $(1.5 \mathrm{~m} \times 1.5 \mathrm{~m}$ each $)$ in each sub-plot of $30 \mathrm{~m} \times 30 \mathrm{~m}$. Each quadrat consists of 9 sub-quadrats of $0.5 \mathrm{~m} \times 0.5 \mathrm{~m}$. The sub-quadrat identification number (1-9) is the order that we used to sample grass each time, e.g., Sub-quadrat 1 was used the first time of any year, 2 was used in second time of the same year, etc.

Grass samples in each sub-quadrat $(0.5 \mathrm{~m} \times 0.5 \mathrm{~m})$ were collected and recorded in the same way through the years. It was cut to the ground level using shears and then packed and weighed, after removing all residual litter and other non-plant materials. The sampling record included latitude, longitude, elevation, grassland types, dominant species, grassland vegetation coverage, grass height, the fresh weight and dry weight (after being dried in the lab at $64{ }^{\circ} \mathrm{C}$ until the weight remained constant).

In the field, we also collected spectral data of grassland, in a total of 18 out of the 20 field campaigns at 1170 sub-quadrats. These data were used to analyze the influence of the three filtering methods on MODIS NDVI. The spectral data were acquired using an AvaField-3 portable spectrometer (made by Holland Avantes Company). The spectral range of AvaField-3 is 300-2500 nm, particularly with a resolution of $1.4 \mathrm{~nm}$ and a sampling interval of $0.6 \mathrm{~nm}$ in the $300-1100 \mathrm{~nm}$ and a resolution of $15 \mathrm{~nm}$ and a sampling interval of $6 \mathrm{~nm}$ in 1100-2500 nm. The fieldwork was conducted on several consecutive sunny days. Measurements were taken on clear sunny days between 11:30 a.m. and 2:00 p.m. The fiber optic sensor, with a field view of $25^{\circ}$, was pointed on the target at nadir position from about a 1-m height above the ground surface. In order to increase the stability and precision of the instrument as advised in the operational manual, we preheated the spectrometer for half an hour before measurements. For each target measurement, the downwelling radiance was first measured by pointing to the white reference panel. The spectral reflectivity was directly recorded by using the upwelling radiance (i.e., reflective radiance) to the target divided by the downwelling radiance. Ten spectral reflectivity curves for each target were collected for later processing in the lab. An example of the mean spectrum of 13 sample plots on 28-29 July 2014 is shown in Figure 2. The artifacts seen (in the Figure 3) around $1150 \mathrm{~nm}$ could be mostly due to the mixed effect of different objects in the sample plots, including grass, soil, gravel and dead grass.

In addition, a portable GPS device for 20 ground control points (GCP) was used in the study to record the longitude, latitude and elevation, for later precise geometric corrections of the Landsat and HJ-1B satellite images. 


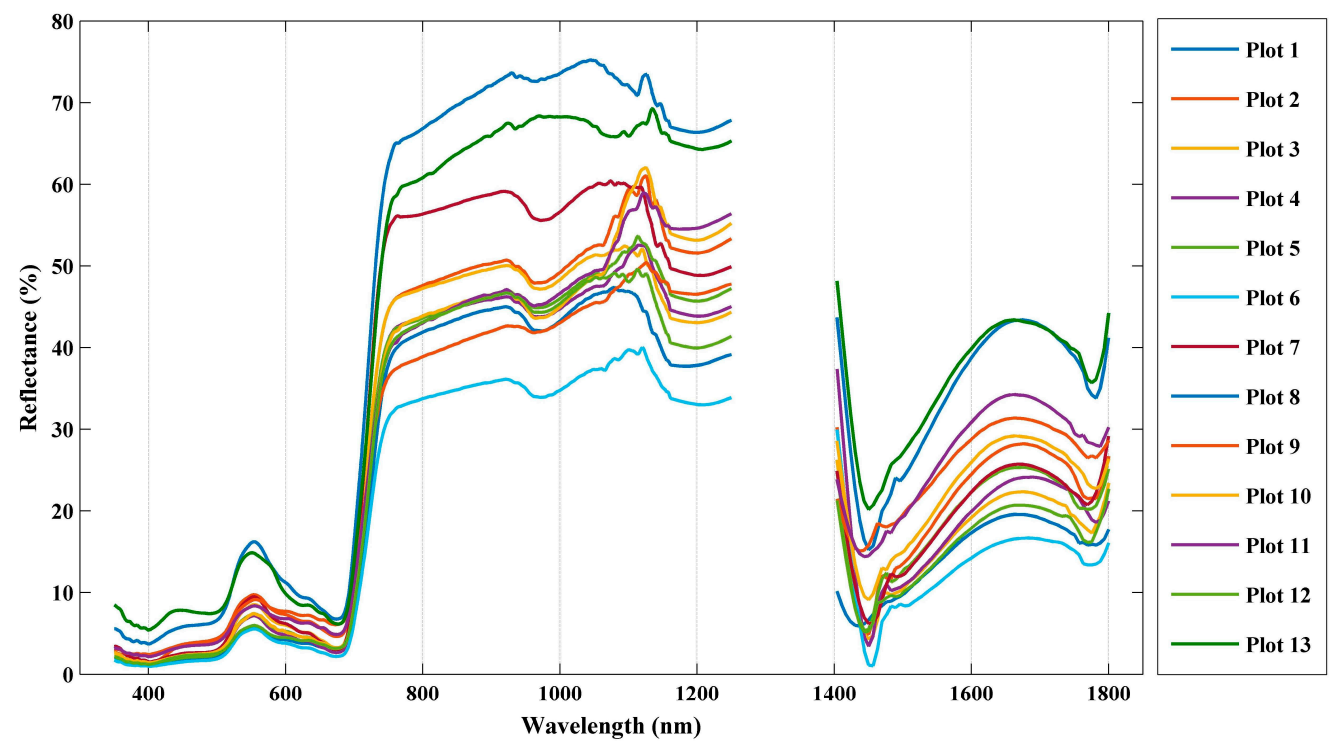

Figure 3. The spectral curves of 13 sample plots on 28-29 July 2014.

\subsection{Preprocessing of MODIS Vegetation Index Data}

The MODIS vegetation index data were selected from the MODIS 16-d maximum composite NDVI vegetation index product (MOD13Q1) of the United States National Aeronautics and Space Administration. In total, 69 images spanning the years 2013-2015 taken with a spatial resolution of $250 \mathrm{~m}$ from orbit number h26v05 were selected. Three filtering methods, the asymmetric Gaussian function (GA), double-logistic curve (LO) and Savitzky-Golay (SG), were used to reconstruct the time series data of NDVI. The four vegetation indices were denoted as $\mathrm{NDVI}_{\mathrm{MOD}}$ (MOD13Q1 NDVI), $\mathrm{NDVI}_{\mathrm{GA}}$ (after GA filtering), $\mathrm{NDVI}_{\mathrm{LO}}$ (after LO filtering) and $\mathrm{NDVI}_{\mathrm{SG}}$ (after SG filtering). The performance of the three filtering methods was examined using the NDVI values derived from spectrum measurements in the 18 out of 20 field campaigns, as shown in Table 1.

Table 1. The dates between MODIS images (h26v05) and spectral measurements in 13 sample plots in the study area.

\begin{tabular}{cc}
\hline Date of MODIS & Measurement Time \\
\hline $2013.08 .30-09.14$ & $2013.09 .12-09.13$ \\
$2014.05 .26-06.10$ & $2014.05 .30-05.31$ \\
$2014.06 .11-06.26$ & $2014.06 .14-06.16$ \\
$2014.06 .27-07.12$ & $2014.06 .28-06.29$ \\
$2014.07 .13-07.28$ & $2014.07 .11-07.13$ \\
$2014.07 .13-07.28$ & $2014.07 .26-07.28$ \\
$2014.08 .14-08.29$ & $2014.08 .14-08.15$ \\
$2014.08 .30-09.14$ & $2014.09 .01-09.02$ \\
$2014.09 .15-09.30$ & $2014.09 .26-09.28$ \\
$2014.10 .17-11.01$ & $2014.10 .20-10.22$ \\
$2015.05 .10-05.25$ & $2015.05 .20-05.22$ \\
$2015.07 .13-07.28$ & $2015.07 .14-07.15$ \\
$2015.07 .13-07.28$ & $2015.07 .24-07.25$ \\
$2015.07 .29-08.13$ & $2015.08 .10-08.11$ \\
$2015.08 .14-08.29$ & $2015.08 .20-08.23$ \\
$2015.08 .30-09.14$ & $2015.09 .11-09.13$ \\
$2015.10 .01-10.16$ & $2015.10 .10-10.11$ \\
$2015.10 .17-11.01$ & $2015.10 .20-10.22$ \\
\hline
\end{tabular}


For the period of field sampling in August 2013, July 2014 and July, August and September 2015, the $\mathrm{NDVI}_{\mathrm{MOD}}, \mathrm{NDVI}_{\mathrm{GA}}, \mathrm{NDVI}_{\mathrm{LO}}$ and $\mathrm{NDVI}_{\mathrm{SG}}$ were used to construct the grassland AGB models, and the performance of the models was assessed using the field measurements.

\subsection{Data Processing of Landsat 8 OLI and HJ-1B CCD and Calculation of the Vegetation Index}

The Landsat 8 OLI data were obtained from the website of the United States Geological Survey (USGS). The OLI imager includes eight multi-spectral bands with a spatial resolution of $30 \mathrm{~m}$ and one panchromatic band with a spatial resolution of $15 \mathrm{~m}$. The imaging range is $185 \mathrm{~km} \times 185 \mathrm{~km}$, and the revisit period is $16 \mathrm{~d}$. In this study, five scenes of Landsat 8 OLI satellite images with no cloud cover in the study area in Xiahe County, Gansu Province, during 2013-2015 were downloaded. The HJ-1B CCD data were acquired from the China Center for Resource Satellite Data and Applications (http://www.cresda.com/n16/index.html). The Environment and Disaster Monitoring Satellite B (HJ-1B) carries two CCD cameras. Each CCD creates four multi-band images with a spatial resolution of $30 \mathrm{~m}$; the frame width of a single CCD image is $360 \mathrm{~km}$. Together, the frame width of the two CCD images spans $700 \mathrm{~km}$, and the revisit period is $4 \mathrm{~d}$. Based on the time of the ground surveys, the revisiting periods of the Landsat 8 and the $\mathrm{HJ}-1 \mathrm{~B}$ satellites and cloud cover in the images, a total of five scenes of the HJ-1B CCD images and five scenes of Landsat 8 images close to the field investigation times that cover the entire study area without clouds (Table 2) were selected.

Table 2. The date between satellite images and field measurements in the study area.

\begin{tabular}{cccccc}
\hline Date of Satellite Images & Satellite & Sensor Type & Path & Row & Sampling Time \\
\hline 2013.08 .08 & Landsat8 & OLI & 131 & 36 & $2013.08 .06-09$ \\
2013.08 .09 & HJ-1B & CCD2 & 12 & 73 & $2013.08 .06-09$ \\
$2013.07 .29-08.13$ & MODIS & Terra & 26 & 5 & $2013.08 .06-08.09$ \\
2014.07 .26 & Landsat8 & OLI & 131 & 36 & $2014.07 .27-31$ \\
2014.07 .28 & HJ-1B & CCD2 & 13 & 72 & $2014.07 .27-31$ \\
$2014.07 .29-08.13$ & MODIS & Terra & 26 & 5 & $2014.07 .27-07.31$ \\
2015.07 .13 & Landsat8 & OLI & 131 & 36 & $2015.07 .11-17$ \\
2015.07 .13 & HJ-1B & CCD1 & 20 & 72 & $2015.07 .11-17$ \\
$2015.07 .13-07.28$ & MODIS & Terra & 26 & 5 & $2015.07 .11-07.17$ \\
2015.08 .14 & Landsat8 & OLI & 131 & 36 & $2015.08 .10-11$ \\
2015.08 .12 & HJ-1B & CCD2 & 16 & 72 & $2015.08 .10-11$ \\
$2015.07 .29-08.13$ & MODIS & Terra & 26 & 5 & $2015.08 .10-08.11$ \\
2015.09 .15 & Landsat8 & OLI & 131 & 36 & $2015.09 .14-18$ \\
2015.09 .14 & HJ-1B & CCD1 & 19 & 72 & $2015.09 .14-18$ \\
$2015.09 .15-09.30$ & MODIS & Terra & 26 & 5 & $2015.09 .14-09.18$ \\
\hline
\end{tabular}

The OLI and CCD data were both processed using ENVI 5.0 software, and the Radiometric Calibration module, the Image to Image module in the registration and the FLAASH Atmospheric Correction module were used for converting the original DN value to atmospheric surface reflectance, precise geometric correction and atmospheric correction of OLI and CCD images, respectively. The image projection was defined as WGS_1984_UTM_ZONE_47N [26]. Then, the Band Math module was used to calculate the NDVI values for the Landsat 8 OLI and HJ-1B CCD images. The NDVI values were extracted from the Landsat $8 \mathrm{OLI}$ and HJ-1B CCD images in the 13 sample sub-plots $(250 \mathrm{~m} \times 250 \mathrm{~m})$. These results were used as the NDVI values (namely, $\mathrm{NDVI}_{\mathrm{CCD}}$ and $\mathrm{NDVI}_{\mathrm{OLI}}$ ) corresponding to the ground sampling sites. 


\subsection{Spectral Data Processing and Accuracy Evaluation of MODIS NDVI}

The spectral data were processed by using the Viewer 7 software of AvaField-3. First, we previewed the spectral curves in the Viewer and removed the abnormal curves. Then, we calculated the mean value of the normal curves for each plot. Third, according to the spectral response function of the MODIS sensor, the reflectance of the red and near-infrared bands corresponding to the MODIS sensor (near-infrared band: 841-876 nm; red band: 620-670 nm) was calculated (Equation (1)). Finally, the NDVI was calculated as Equation (2).

$$
\rho_{i}=\frac{\sum_{\lambda_{a i}}^{\lambda_{b i}} \varphi\left(\lambda_{i}\right) \psi\left(\lambda_{i}\right)}{\sum_{\lambda_{a i}}^{\lambda_{b i}} \varphi\left(\lambda_{i}\right)}
$$

where $\rho_{i}$ represents the reflectivity of band $i, \lambda_{a i}$ represents the starting wavelength of band $i, \lambda_{b i}$ represents the termination wavelength of band $i, \psi\left(\lambda_{i}\right)$ represents the reflectivity value at wavelength $\lambda$ and $\varphi\left(\lambda_{i}\right)$ represents the spectral response factor at wavelength $\lambda$ of band $i$.

$$
\mathrm{NDVI}=\left(\rho_{\text {Nir }}-\rho_{\text {Red }}\right) /\left(\rho_{\text {Nir }}+\rho_{\text {Red }}\right)
$$

where $\rho_{\text {Nir }}$ represents the reflectance of the near-infrared band and $\rho_{\text {Red }}$ represents the reflectance of the red band.

According to the measured spectrum of grassland in the sub-quadrat, the NDVI values of the grassland were calculated by taking the average NDVI of the five quadrats as the ground-measured NDVI value for that sub-plot and then calculating the root mean square error (RMSE) with $\mathrm{NDVI}_{\mathrm{MOD}}$, $\mathrm{NDVI}_{\mathrm{GA}}, \mathrm{NDVI}_{\mathrm{LO}}$ and NDVI $\mathrm{SG}$ (Equation (3)) and their correlation coefficients $(r)$. The smaller the RMSE and the larger the $r$ value are, the better the vegetation index.

$$
\mathrm{RMSE}=\sqrt{\frac{\sum_{i=1}^{n}\left(\mathrm{y}_{i}-\mathrm{y}_{i}^{\prime}\right)^{2}}{\mathrm{n}}}
$$

where $\mathrm{y}_{i}$ represents the ground-measured value, $\mathrm{y}_{i}^{\prime}$ is the estimated value, $i$ represents a sampling plot and $\mathrm{n}$ stands for the number of sample plots.

\subsection{Construction of Grassland Biomass Monitoring Model and Accuracy Evaluation}

The average dry weight of AGB in all of the sub-quadrats of each sub-plot was estimated as the biomass for that sample plot. Taking the grassland biomass of different sample plots as the dependent variable and taking $\mathrm{NDVI}_{\mathrm{MOD}}, \mathrm{NDVI}_{\mathrm{GA}}, \mathrm{NDVI}_{\mathrm{LO}}, \mathrm{NDVI}_{\mathrm{SG}}, \mathrm{NDVI}_{\mathrm{CCD}}$ and $\mathrm{NDVI}_{\mathrm{OLI}}$ as the independent variables, the leave-one-out cross validation (LOOCV) method, RMSE and relative estimate error (REE) (Equation (4)) were used to evaluate the accuracy and estimation errors of the linear, exponential, logarithmic and power regression models for the 6 vegetation indices at the sample plot level.

$$
\mathrm{REE}=\sqrt{\frac{\sum_{i=1}^{n}\left[\left(\mathrm{y}_{i}-\mathrm{y}_{i}^{\prime}\right) / \mathrm{y}_{i}^{\prime}\right]^{2}}{\mathrm{n}}}
$$

where $\mathrm{y}_{i}$ represents the ground-measured value, $\mathrm{y}_{i}^{\prime}$ is the estimated value, $i$ represents a sampling plot and $\mathrm{n}$ stands for the number of sample plots.

In addition, to study the relative estimation error of the alpine meadow grassland AGB monitoring model on the regional scale (i.e., the experimental area of this study), the average AGB dry weight for all of the sample plots in each sample area was adopted as the ground-measured biomass in this sample area. Then, the RMSE and REE were used to assess the performance of each model for estimating total yield and yield per unit area. 


\section{Results and Analysis}

\subsection{Statistical Analysis of Ground Observation AGB and the Corresponding Multi-Source Satellite NDVI}

Table 3 shows the statistical results of AGB in the surveyed sample plots and the NDVI calculated using the corresponding remote sensing data from 2013-2015. There are considerable differences in the biomass during the grass growing season in the 13 sample plots of the experimental area. The average values range from $1280-1887 \mathrm{~kg}$ DW/ ha over the past three years, while the coefficient of variation ranges from $0.16-0.73$. The largest biomass from the 13 sample plots is $3963 \mathrm{~kg} \mathrm{DW} / \mathrm{ha}$, and the minimum is $745.5 \mathrm{~kg} \mathrm{DW} / \mathrm{ha}$. The magnitude of the variation in the $\mathrm{NDVI}_{\mathrm{CCD}}, \mathrm{NDVI}_{\mathrm{OLI}}$ and $\mathrm{NDVI}_{\mathrm{MOD}}$ values is relatively small, and their dispersion degree is similar; the standard deviation and coefficient of variation range from $0.03-0.13$ and $0.05-0.18$, respectively. In terms of mean NDVI value ranges, they are very similar, from $0.59-0.75$ and $0.57-0.74$, respectively, for $\mathrm{NDVI}_{\mathrm{CCD}}$ and $\mathrm{NDVI}_{\mathrm{MOD}}$ and $0.62-0.83$ for $\mathrm{NDVI}_{\mathrm{OLI}}$, slightly larger than the former two.

For the entire experimental area, the average total biomass in August 2013-2015 is $285 \times 10^{3} \mathrm{~kg}$, and the average grass yield is $1813.5 \mathrm{~kg} \mathrm{DW} / \mathrm{ha}$. In the experimental area, the average biomass of the five times in July-September of 2013-2015 is $1808.4 \mathrm{~kg}$ DW/ha, with the standard deviation of $847.3 \mathrm{~kg}$ DW/ha and the variation coefficient of 0.47 . Similar to the sample plots level, the $\mathrm{NDVI}_{\mathrm{CCD}}$ and $\mathrm{NDVI}_{\mathrm{MOD}}$ means are very close (0.68-0.69), slightly smaller than the 0.78 of $\mathrm{NDVI}_{\mathrm{OLI}}$.

\subsection{Influence of Different Filtering Methods on MODIS NDVI}

The NDVI calculated using the measured spectrum data on the ground is treated as the ground-measured value to examine the accuracy of $\mathrm{NDVI}_{\mathrm{MOD}}$ and the three NDVI time series after the filters are applied, i.e., $\mathrm{NDVI}_{\mathrm{GA}}, \mathrm{NDVI}_{\mathrm{LO}}$ and $\mathrm{NDVI}_{\mathrm{SG}}$. The results are shown in Table 4, indicating that the three filtering methods perform better overall than the original MOD13Q1 NDVI, and the SG filtering is the best. At the sample plot level, the SG filtering method achieves the best results for Sample Plots 1, 4-8, 10, 12 and 13, with RMSE ranging from 0.028-0.098 and $r$ values ranging from 0.78-0.91. The logistic filtering method achieved the best results for Sample Plots 3 and 11; with RMSE of $0.050-0.076$ and $r$ values of $0.88-0.89$. The Gaussian filtering method achieved the best results for Sample Plots 2 and 9; with RMSE of 0.078-0.094 and $r$ values of 0.81-0.89. Among all of the sample plots, all three filtering methods achieved relatively good results at Plot 1, with RMSE of 0.028-0.029 and $r$ of $0.90-0.91$. In contrast, all three filtering methods achieve relatively poor results at Plot 13 , with RMSE values ranging from $0.098-0.113$ and $r$ values from $0.85-0.91$. 
Table 3. Descriptive statistics of grassland above-ground biomass (AGB) and corresponding multi-source satellite NDVI during July-September of 2013-2015 in the study area, Xiahe County.

\begin{tabular}{|c|c|c|c|c|c|c|c|c|c|c|c|c|c|c|c|}
\hline \multirow{2}{*}{ Index } & \multirow{2}{*}{ Statistics } & \multicolumn{14}{|c|}{ Plot } \\
\hline & & E1 & E2 & E3 & E4 & E5 & E6 & E7 & D8 & D9 & $\mathrm{C} 10$ & B11 & A12 & A13 & All \\
\hline \multirow{6}{*}{ Biomass $\left(10^{3} \mathrm{~kg} / \mathrm{ha}\right)$} & Maximum & 2.20 & 2.28 & 2.70 & 2.08 & 2.52 & 2.94 & 3.20 & 2.47 & 1.77 & 2.03 & 2.41 & 3.96 & 2.67 & 3.96 \\
\hline & Minimum & 1.12 & 1.15 & 0.83 & 0.86 & 0.79 & 1.13 & 0.97 & 0.94 & 1.18 & 0.95 & 0.93 & 0.83 & 0.75 & 0.75 \\
\hline & Average & 1.77 & 1.89 & 1.86 & 1.29 & 1.48 & 1.71 & 1.75 & 1.82 & 1.51 & 1.37 & 1.44 & 1.68 & 1.28 & 1.81 \\
\hline & Standard deviation & 0.47 & 0.52 & 0.81 & 0.534 & 0.74 & 0.84 & 1.00 & 0.68 & 0.25 & 0.46 & 0.67 & 1.52 & 0.93 & 0.85 \\
\hline & $\mathrm{Cv}$ & 0.27 & 0.27 & 0.44 & 0.42 & 0.50 & 0.50 & 0.57 & 0.37 & 0.16 & 0.34 & 0.47 & 0.12 & 0.73 & 0.47 \\
\hline & $\mathrm{n}$ & 25 & 25 & 25 & 25 & 25 & 25 & 25 & 25 & 25 & 25 & 25 & 25 & 25 & 325 \\
\hline \multirow{6}{*}{ HJ-CCD NDVI } & Maximum & 0.68 & 0.74 & 0.80 & 0.76 & 0.80 & 0.78 & 0.73 & 0.74 & 0.68 & 0.71 & 0.71 & 0.67 & 0.67 & 0.80 \\
\hline & Minimum & 0.57 & 0.64 & 0.67 & 0.62 & 0.68 & 0.64 & 0.65 & 0.65 & 0.62 & 0.58 & 0.57 & 0.53 & 0.51 & 0.51 \\
\hline & Average & 0.65 & 0.71 & 0.75 & 0.67 & 0.73 & 0.72 & 0.70 & 0.70 & 0.65 & 0.64 & 0.64 & 0.61 & 0.59 & 0.68 \\
\hline & Standard deviation & 0.04 & 0.05 & 0.05 & 0.07 & 0.05 & 0.06 & 0.04 & 0.04 & 0.03 & 0.05 & 0.06 & 0.06 & 0.07 & 0.07 \\
\hline & $\mathrm{CV}_{\mathrm{V}}$ & 0.07 & 0.07 & 0.06 & 0.10 & 0.07 & 0.08 & 0.06 & 0.05 & 0.05 & 0.08 & 0.09 & 0.09 & 0.12 & 0.10 \\
\hline & $\mathrm{n}$ & 5 & 5 & 5 & 5 & 5 & 5 & 5 & 5 & 5 & 5 & 5 & 5 & 5 & 65 \\
\hline \multirow{6}{*}{ Landsat-8 OLI DVI } & Maximum & 0.77 & 0.86 & 0.90 & 0.86 & 0.87 & 0.86 & 0.85 & 0.87 & 0.82 & 0.78 & 0.82 & 0.79 & 0.71 & 0.97 \\
\hline & Minimum & 0.60 & 0.70 & 0.74 & 0.65 & 0.73 & 0.73 & 0.75 & 0.76 & 0.63 & 0.66 & 0.69 & 0.64 & 0.55 & 0.55 \\
\hline & Average & 0.70 & 0.79 & 0.84 & 0.755 & 0.81 & 0.80 & 0.81 & 0.82 & 0.72 & 0.72 & 0.75 & 0.70 & 0.62 & 0.78 \\
\hline & Standard deviation & 0.07 & 0.07 & 0.07 & 0.10 & 0.06 & 0.06 & 0.05 & 0.05 & 0.08 & 0.06 & 0.06 & 0.07 & 0.07 & 0.10 \\
\hline & $\mathrm{Cv}$ & 0.10 & 0.09 & 0.08 & 0.13 & 0.08 & 0.08 & 0.06 & 0.06 & 0.11 & 0.08 & 0.08 & 0.10 & 0.11 & 0.13 \\
\hline & $\mathrm{n}$ & 5 & 5 & 5 & 5 & 5 & 5 & 5 & 5 & 5 & 5 & 5 & 5 & 5 & 65 \\
\hline \multirow{6}{*}{ MOD13Q1 NDVI } & Maximum & 0.82 & 0.84 & 0.82 & 0.82 & 0.81 & 0.81 & 0.82 & 0.79 & 0.73 & 0.75 & 0.79 & 0.69 & 0.67 & 0.84 \\
\hline & Minimum & 0.66 & 0.69 & 0.68 & 0.65 & 0.61 & 0.64 & 0.64 & 0.58 & 0.62 & 0.46 & 0.49 & 0.49 & 0.44 & 0.44 \\
\hline & Average & 0.73 & 0.74 & 0.73 & 0.72 & 0.70 & 0.71 & 0.72 & 0.69 & 0.68 & 0.60 & 0.60 & 0.57 & 0.58 & 0.69 \\
\hline & Standard deviation & 0.06 & 0.07 & 0.07 & 0.07 & 0.08 & 0.07 & 0.08 & 0.08 & 0.05 & 0.12 & 0.13 & 0.09 & 0.10 & 0.10 \\
\hline & $C_{V}$ & 0.09 & 0.09 & 0.09 & 0.10 & 0.12 & 0.10 & 0.11 & 0.12 & 0.07 & 0.20 & 0.21 & 0.15 & 0.18 & 0.15 \\
\hline & $\mathrm{n}$ & 5 & 5 & 5 & 5 & 5 & 5 & 5 & 5 & 5 & 5 & 5 & 5 & 5 & 65 \\
\hline
\end{tabular}

Note: $\mathrm{Cv}$ depicts the coefficient of variation, equal to the standard deviation divided by the mean; $\mathrm{n}$ depicts the number of observations. 
Table 4. The result of $\mathrm{NDVI}_{\mathrm{MOD}}, \mathrm{NDVI}_{\mathrm{GA}}, \mathrm{NDVI}_{\mathrm{LO}}$ and $\mathrm{NDVI} \mathrm{SG}_{\mathrm{SG}}$ as compared with the field measurements in 13 sample plots of the study area.

\begin{tabular}{|c|c|c|c|c|c|c|c|c|c|c|c|c|c|c|c|}
\hline \multirow{2}{*}{$\begin{array}{l}\text { Vegetation } \\
\text { Index }\end{array}$} & \multirow{2}{*}{ Index } & \multicolumn{14}{|c|}{ Plot } \\
\hline & & E1 & E2 & E3 & E4 & E5 & E6 & E7 & D8 & DB9 & C10 & B11 & A12 & A13 & Average \\
\hline \multirow{2}{*}{$\mathrm{NDVI}_{\mathrm{MOD}}$} & RMSE & 0.035 & 0.083 & 0.081 & 0.079 & 0.087 & 0.089 & 0.105 & 0.115 & 0.110 & 0.087 & 0.051 & 0.120 & 0.111 & 0.102 \\
\hline & $\mathrm{R}$ & $0.83 * *$ & $0.85^{* *}$ & $0.86^{* *}$ & $0.83 * *$ & $0.81^{* *}$ & $0.81^{* *}$ & $0.78^{* *}$ & 0.70 & $0.74^{* *}$ & $0.82 * *$ & $0.87^{* *}$ & 0.82 & $0.77^{* *}$ & $0.77^{* *}$ \\
\hline \multirow{2}{*}{$\mathrm{NDVI}_{\mathrm{GA}}$} & RMSE & 0.029 & 0.078 & 0.077 & 0.062 & 0.077 & 0.070 & 0.087 & 0.094 & 0.094 & 0.079 & 0.051 & 0.113 & 0.107 & 0.091 \\
\hline & $\mathrm{R}$ & $0.90 * *$ & 0.89 ** & $0.88^{* *}$ & $0.90 * *$ & $0.86^{* *}$ & $0.89^{* *}$ & $0.86^{* *}$ & 0.82 * & $0.81^{* *}$ & $0.86^{* *}$ & $0.89^{* *}$ & $0.85^{* *}$ & $0.79 * *$ & $0.83^{* *}$ \\
\hline \multirow{2}{*}{$\mathrm{NDVI}_{\mathrm{LO}}$} & RMSE & 0.028 & 0.078 & 0.076 & 0.062 & 0.077 & 0.072 & 0.088 & 0.095 & 0.095 & 0.080 & 0.050 & 0.112 & 0.107 & 0.091 \\
\hline & $\mathrm{R}$ & $0.90 * *$ & 0.89 ** & $0.88^{* *}$ & $0.90 * *$ & $0.86^{* *}$ & $0.88^{* *}$ & $0.86^{* *}$ & 0.81 * & $0.80 * *$ & $0.86^{* *}$ & $0.89^{* *}$ & $0.86^{* *}$ & $0.78^{* *}$ & $0.83 * *$ \\
\hline \multirow{2}{*}{$\mathrm{NDVI}_{\mathrm{SG}}$} & RMSE & 0.028 & 0.079 & 0.080 & 0.060 & 0.075 & 0.070 & 0.085 & 0.093 & 0.095 & 0.078 & 0.051 & 0.098 & 0.107 & 0.090 \\
\hline & $\mathrm{R}$ & $0.91 * *$ & $0.88^{* *}$ & $0.87^{* *}$ & $0.91 * *$ & $0.87^{*}$ & $0.89^{* *}$ & $0.86^{* *}$ & 0.82 * & $0.81^{* *}$ & $0.88^{* *}$ & $0.88^{* *}$ & $0.91^{* *}$ & $0.78^{* *}$ & $0.84^{* *}$ \\
\hline
\end{tabular}


3.3. Grassland Biomass Monitoring Model in the Study Area and Evaluation of Its Accuracy at the Sample Plot Level

The results of the accuracy evaluation validated by LOOCV for the grassland biomass models constructed on the three satellites, $\mathrm{NDVI}_{\mathrm{MOD}}, \mathrm{NDVI}_{\mathrm{CCD}}$ and $\mathrm{NDVI}_{\mathrm{OLI}}$, as well as the three filtering methods applied to MODIS NDVI only are listed in Table 5. It is found that in the four types of grassland AGB estimation models (linear, logarithmic, power and exponential), the exponential model performs the best, with the smallest RMSE and REE, while the linear or power model performs the second best. Among the six vegetation indices, the exponential model based on NDVI $\mathrm{OLI}_{\mathrm{L}}$ is the best, with the smallest RMSE of $511.6 \mathrm{~kg}$ DW/ha and REE of $29.1 \%$ and the highest estimation accuracy of the AGB (Figure 4d). The exponential model based on $\mathrm{NDVI}_{\mathrm{CCD}}$ is the second best (Figure 4c). The exponential model based on $\mathrm{NDVI}_{\mathrm{MOD}}$ is worse (Figure 4a). All of the filtering methods perform better than the NDVI $\mathrm{MOD}_{\text {, with }} \mathrm{NDVI}_{\mathrm{SG}}$ the best (Figure $4 \mathrm{~b}$ ).

Table 6 shows the parameters of the best fit model for each of the six vegetation indices. As shown, all six models pass the $T$ test and $F$ test at a significance level of 0.01 , with $\mathrm{NDVI}_{\mathrm{OLI}}$ the best, followed by $\mathrm{NDVI}_{\mathrm{CCD}}, \mathrm{NDVI}_{\mathrm{SG}}$ and $\mathrm{NDVI}_{\mathrm{MOD}}$.

Table 5. The validation results by leave-one-out cross validation for the grassland biomass models based on multi-source satellite data. REE, relative estimate error.

\begin{tabular}{cccc}
\hline \multirow{2}{*}{ Vegetation Index } & Model & \multicolumn{2}{c}{ Accuracy Evaluation } \\
\cline { 3 - 4 } & & RMSE (kg/ha) & REE (\%) \\
\hline \multirow{2}{*}{ NDVI $_{\text {MOD }}$} & Linear & 594.5 & 47.8 \\
& Exponential & 574.6 & 35.3 \\
& Logarithm & 619.2 & 61.4 \\
& Power & 598.8 & 36.7 \\
\hline \multirow{2}{*}{ NDVI $_{\text {SG }}$} & Linear & 573.3 & 45.0 \\
& Exponential & 549.7 & 33.9 \\
& Logarithm & 594.6 & 57.7 \\
& Power & 571.4 & 35.0 \\
\hline \multirow{2}{*}{ NDVI $_{\text {LO }}$} & Linear & 581.1 & 44.1 \\
& Exponential & 560.4 & 34.1 \\
& Logarithm & 602.4 & 53.8 \\
& Power & 582.0 & 35.2 \\
\hline \multirow{2}{*}{ NDVI $_{\mathrm{GA}}$} & Linear & 583.8 & 44.2 \\
& Exponential & 562.0 & 34.1 \\
& Logarithm & 605.8 & 53.9 \\
& Power & 585.2 & 35.3 \\
\hline & Linear & 557.1 & 45.2 \\
NDVI $_{\mathrm{OLI}}$ & Exponential & 548.4 & 31.6 \\
& Logarithm & 567.6 & 74.0 \\
& Power & 552.6 & 32.1 \\
\hline \multirow{2}{*}{ NDVI $_{\mathrm{CCD}}$} & Linear & 516.8 & 33.7 \\
& Exponential & 511.6 & 29.1 \\
& Logarithm & 528.9 & 51.2 \\
\hline & Power & 512.1 & \\
\hline
\end{tabular}



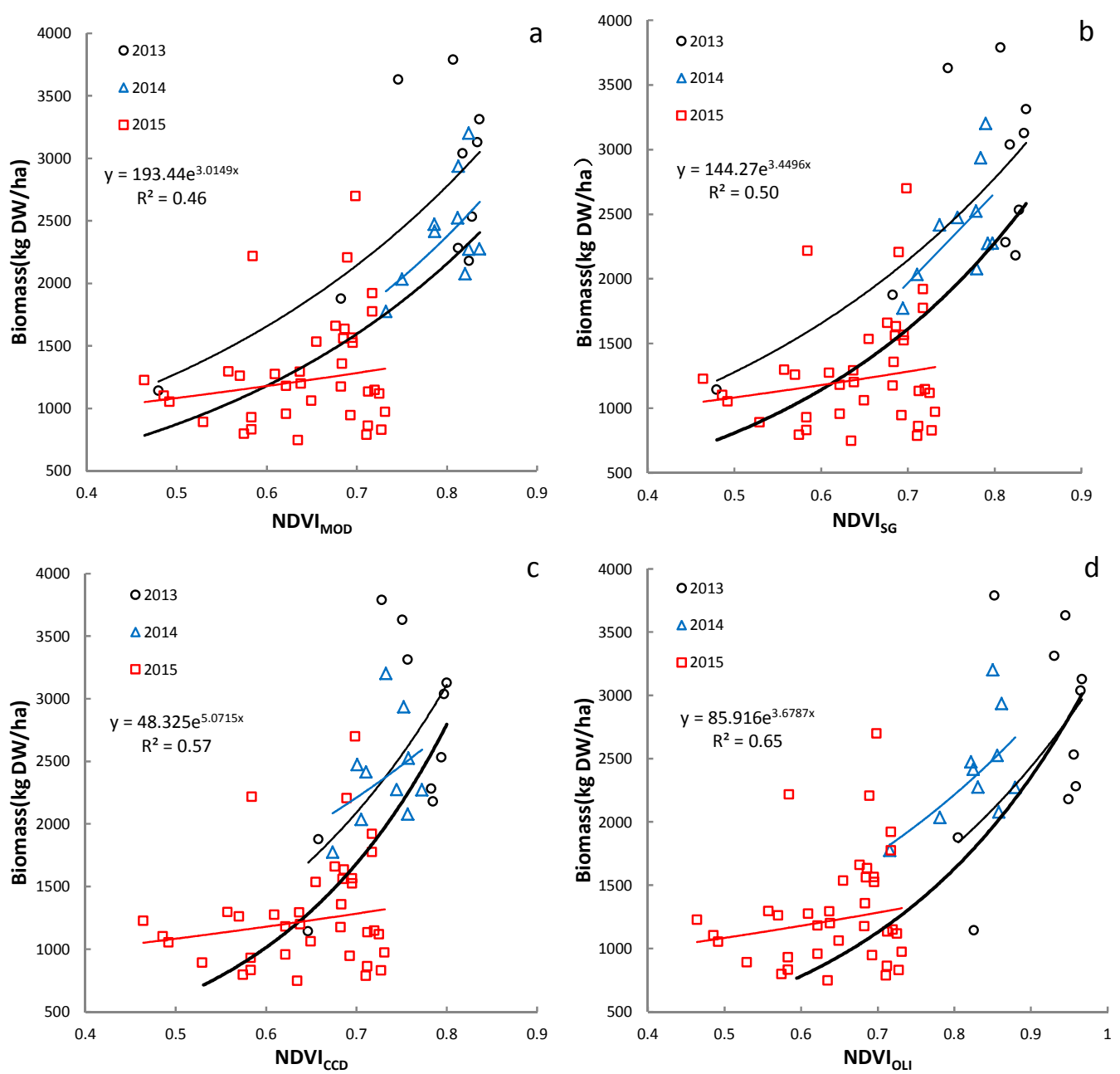

Figure 4. The best fit models constructed based on $\operatorname{NDVI}_{\mathrm{MOD}}(\mathbf{a}), \mathrm{NDVI}_{\mathrm{SG}}(\mathbf{b}), \mathrm{NDVI}_{\mathrm{CCD}}(\mathbf{c})$ and $\operatorname{NDVI}_{\text {OLI }}(\mathbf{d})$.

Table 6. The results of model fits with the optimum inversion models based on multi-source satellite data.

\begin{tabular}{cccccc}
\hline \multirow{2}{*}{ Vegetation Index } & \multicolumn{2}{c}{ Parameter Estimation and Test } & \multicolumn{2}{c}{ Regression Significance Test } \\
\cline { 2 - 6 } & Parameter & Estimated Value & $\boldsymbol{T}$ & $\mathbf{R}^{\mathbf{2}}$ & $\boldsymbol{F}$ \\
\hline \multirow{2}{*}{$\mathrm{NDVI}_{\mathrm{MOD}}$} & $\mathrm{b}$ & 3.0149 & $6.817^{* *}$ & 0.46 & $46.478^{* *}$ \\
& $\mathrm{a}$ & 193.442 & $3.229^{* *}$ & & \\
\hline \multirow{2}{*}{ NDVI $_{\mathrm{SG}}$} & $\mathrm{b}$ & 3.4496 & $7.400^{* *}$ & 0.50 & $54.759^{* *}$ \\
& $\mathrm{a}$ & 144.265 & $3.078^{* *}$ & & \\
\hline \multirow{2}{*}{$\mathrm{NDVI}_{\mathrm{LO}}$} & $\mathrm{b}$ & 3.496 & $7.030^{* *}$ & 0.47 & $49.413^{* *}$ \\
& $\mathrm{a}$ & 140.404 & $2.888^{* *}$ & & \\
\hline \multirow{2}{*}{$\mathrm{NDVI}_{\mathrm{GA}}$} & $\mathrm{b}$ & 3.487 & $6.889^{* *}$ & 0.46 & $47.464^{* *}$ \\
& $\mathrm{a}$ & 141.383 & $2.839^{* *}$ & & \\
\hline \multirow{2}{*}{$\mathrm{NDVI}_{\mathrm{CCD}}$} & $\mathrm{b}$ & 5.0715 & $8.581^{* *}$ & 0.57 & $73.634^{* *}$ \\
& $\mathrm{a}$ & 48.325 & $2.457^{* *}$ & & \\
\hline \multirow{2}{*}{$\mathrm{NDVI}_{\mathrm{OLI}}$} & $\mathrm{b}$ & 3.6787 & $10.017^{* *}$ & 0.65 & $100.341^{* *}$ \\
& $\mathrm{a}$ & 85.916 & $3.427^{* *}$ & & \\
\hline
\end{tabular}

Note: ${ }^{* *}$ represents $p<0.01$; a and $\mathrm{b}$ represent the constant and exponential term of the model, respectively; $T$ and $F$ are the significant values according to the $T$ and $F$ tests. 


\section{Discussion}

\subsection{Influence of Different Remote Sensing Data on the Estimation Error of Grassland Biomass}

In this study, $\mathrm{NDVI}_{\mathrm{MOD}}, \mathrm{NDVI}_{\mathrm{CCD}}$ and $\mathrm{NDVI}_{\mathrm{OLI}}$ data were used in combination with ground observation data during 2013-2015 to construct a grassland biomass inversion model. The errors based on $\mathrm{NDVI}_{\mathrm{MOD}}, \mathrm{NDVI}_{\mathrm{CCD}}$ and $\mathrm{NDVI}_{\mathrm{OLI}}$ reached $35.3 \%, 31.6 \%$ and $29.1 \%$, respectively, at the sample plot level (Table 5). Our results indicate that the yield per unit area estimated using the exponential model based on $\mathrm{NDVI}_{\mathrm{OLI}}(1518 \mathrm{~kg} \mathrm{DW} / \mathrm{ha}$ ) is closest to the ground-measured value, and its estimation error is the lowest $(30.7 \%)$, followed by $\operatorname{NDVI}_{\mathrm{CCD}}(32.4 \%)$ and $\mathrm{NDVI}_{\mathrm{MOD}}(39.6 \%)$ (Table 7). This result suggests that the inverse models based on $30-\mathrm{m}$ resolution (namely, $\mathrm{NDVI}_{\mathrm{CCD}}$ and $\mathrm{NDVI}_{\mathrm{OLI}}$ ) are better than that based on MODIS data with 250-m resolution, and the model based on NDVI $\mathrm{OLI}_{\mathrm{I}}$ is better than that on $\mathrm{NDVI}_{\mathrm{CCD}}$.

Table 7. The estimation error of the grassland AGB evaluated by different remote sensing data and filtering methods in study area.

\begin{tabular}{ccccc}
\hline Data Type & Vegetation Index & Formula & Yield (AGB) (kg DW/ha) & REE (\%) \\
\hline \multirow{2}{*}{ Different remote } & NDVI $_{\mathrm{OLI}}$ & $\mathrm{y}=85.916 \mathrm{e}^{3.6787 \mathrm{x}}$ & 1518.0 & 30.7 \\
sensing data & $\mathrm{NDVI}_{\mathrm{CCD}}$ & $\mathrm{y}=48.325 \mathrm{e}^{5.0715 \mathrm{x}}$ & 1472.7 & 32.4 \\
& NDVI $_{\mathrm{MOD}}$ & $\mathrm{y}=193.442 \mathrm{e}^{3.0149 \mathrm{x}}$ & 1431.0 & 39.6 \\
\hline \multirow{2}{*}{$\begin{array}{c}\text { Different filtering } \\
\text { methods }\end{array}$} & $\mathrm{NDVI}_{\mathrm{SG}}$ & $\mathrm{y}=132.146 \mathrm{e}^{3.584 \mathrm{x}}$ & 1564.1 & 34.9 \\
& $\mathrm{NDVI}_{\mathrm{LO}}$ & $\mathrm{y}=140.404 \mathrm{e}^{3.496 \mathrm{x}}$ & 1422.3 & 38.6 \\
& $\mathrm{NDVI}_{\mathrm{GA}}$ & $\mathrm{y}=141.383 \mathrm{e}^{3.478 \mathrm{x}}$ & 1408.1 & 39.3 \\
\hline
\end{tabular}

There are multiple reasons for the above results. Existing studies indicate that the accuracy of the grassland biomass inversion model is not only affected by the temporal and spatial resolutions of the satellite images, sensor type and method of image processing [18,27], but is also subject to the influence of the size, number and representativeness of ground sampling sites. In this study, the five-point method is adopted to determine the sub-plot $(30 \mathrm{~m} \times 30 \mathrm{~m})$, which matches the spatial resolution of the Landsat 8 OLI and HJ-1B CCD images. Although the Landsat or HJ-1B pixel could not always exactly match a sub-plot $(30 \mathrm{~m} \times 30 \mathrm{~m})$ on the ground due to the orbit drift, we consider this a minor problem, since the relatively uniform distribution of grass in each $250 \mathrm{~m} \times 250 \mathrm{~m}$ sample plot was one of the selection criteria. A slight mismatch between sub-plot and satellite pixel does not really make much difference in our case. The average grassland biomass based on five quadrats can reasonably represent the variation of grassland biomass within a full $30 \mathrm{~m} \times 30 \mathrm{~m}$ sub-plot; therefore, the accuracy is relatively high for the grassland biomass monitoring model constructed using the remote sensing image data with $30-\mathrm{m}$ resolution (namely, $\mathrm{NDVI}_{\mathrm{OLI}}$ and $\mathrm{NDVI}_{\mathrm{CCD}}$ ). However, the spatial matching with the MODIS vegetation index, which uses a 250-m spatial resolution, has some limitations; consequently, the accuracy of the simulation model is relatively low. In addition, there is an obvious difference between the estimation errors of the biomass models based on NDVI OLI and $\mathrm{NDVI}_{\mathrm{CCD}}$, which have the same spatial resolution $(30 \mathrm{~m})$. The error of the AGB estimation model based on $\mathrm{NDVI}_{\mathrm{OLI}}$ is smaller than $\mathrm{NDVI}_{\mathrm{CCD}}$. This difference occurred mainly because the near-infrared (NIR) and red bands (RED) used to calculate their NDVI values come from different sensors that have different band ranges. Specifically, the NIR and RED band ranges used to calculate NDVI $\mathrm{CCD}$ are $0.76-0.90 \mu \mathrm{m}$ and $0.63-0.69 \mu \mathrm{m}$, respectively, while for $\mathrm{NDVI}_{\mathrm{OLI}}$, they are $0.845-0.885 \mu \mathrm{m}$ and $0.630-0.680 \mu \mathrm{m}$, respectively. The narrow band receives less signal disturbances. In addition, the OLI NIR also excludes the influence of water vapor absorption at $0.825 \mu \mathrm{m}$, and therefore, the OLI NIR's contribution to retrieve grassland information is more prominent [28]. 


\subsection{Influence of Three Filtering Methods on the Error of Grassland AGB Estimation Based on MODIS NDVI}

The exponential models (based on the accuracy of the best inversion mode) for grassland AGB of the three filtering methods including $\mathrm{NDVI}_{\mathrm{SG}}, \mathrm{NDVI}_{\mathrm{LO}}$ and $\mathrm{NDVI}_{\mathrm{GA}}$, can better simulate the grassland AGB than the $\mathrm{NDVI}_{\mathrm{MOD}}$, in which the error decreased by approximately 1.40, 1.14 and $1.13 \%$, respectively (Table 5). The yield per unit area for grassland AGB estimated by $\mathrm{NDVI}_{\mathrm{SG}}$ (1564.1 kg DW/ha) is the closest to the ground-measured value, and its estimation error was the lowest (34.9\%), followed by $\mathrm{NDVI}_{\mathrm{LO}}$ and $\mathrm{NDVI}_{\mathrm{GA}}$ (Table 7). This result indicates that the SG filtering method is better at eliminating abnormal values from the MOD13Q1 NDVI; consequently, it yields biomass estimates closer to the ground-measured value. This finding is similar to the research results of Chen et al. (2004) and Geng et al. (2014) Their studies in Southeast Asia indicated that SG filtering can partially eliminate atmospheric interference and the influence of mixed pixels on the grassland vegetation index and can improve the representativeness of MODIS NDVI for grassland vegetation $[23,29]$.

\subsection{Assessment of Previously-Established Biomass Inversion Models Based on the MODIS Vegetation Index over the Tibetan Plateau}

Many scholars have used the MODIS vegetation index to conduct numerous successful studies on grassland biomass in the Tibetan Plateau area. However, the existing studies show considerable differences in model errors for alpine grassland in the Tibetan Plateau area at the sample plot scale (Table 8). For example, the grassland biomass inversion model constructed by $\mathrm{Xu}$ et al. (2007) used field measurement data in the Tibetan Plateau area and the 10-d maximum composite MODIS NDVI (with a 1-km resolution) from the end of July to the end of September in 2007, to construct an exponential function (Model I), with $R^{2}$ of 0.75 and overall estimation accuracy up to $80 \%$ [19]. In the grassland biomass regression models constructed by Feng et al. (2011), which combined measurement data from the Tibetan Plateau during July-August of 2005 and 2006 with the monthly maximum composition $1-\mathrm{km}$ resolution MODIS NDVI, the exponential function model is the optimum inversion model (Model II). However, its accuracy is lower than that of Model I; with $\mathrm{R}^{2}$ of 0.49 and RMSE up to $671.8 \mathrm{~kg}$ DW/ha [30]. Cui et al. (2011), Wang et al. (2010) and Bao et al. (2010) used the MODIS vegetation index at 500-m, 1-km and 250-m resolution, respectively, to construct biomass regression models for the Gannan prefecture. Their results are similar. The optimum inversion model (in the order of Models III, IV and V) is a power function based on MODIS EVI, with the $\mathrm{R}^{2}$ values of 0.63 , 0.62 and 0.63 , respectively [31-33]. Clearly, there are large differences among models. Here, we intend to examine the feasibility of these models all developed at large scales to be applied to our small study area with detailed field data.

Table 8. The existing AGB estimation models for alpine grassland in the Tibetan Plateau region.

\begin{tabular}{ccccccc}
\hline Model & Study Area & Area $\mathbf{( 1 0 ^ { 4 }}$ ha) & MODIS & Formula & $\mathbf{R}^{\mathbf{2}}$ & Literature \\
\hline I & Tibetan Plateau & 25,724 & NDVI & $y=225.42 \times \mathrm{e}^{4.4368 x}$ & 0.75 & {$[19]$} \\
\hline II & Tibetan Plateau & 25,724 & NDVI & $y=268.810 \times \mathrm{e}^{2.398 x}$ & 0.49 & {$[30]$} \\
\hline III & $\begin{array}{c}\text { The northeast of Tibetan } \\
\text { Plateau (Gannan Prefecture) }\end{array}$ & 380 & EVI & $y=3738.073 x^{1.553}$ & 0.63 & {$[31]$} \\
\hline IV & $\begin{array}{c}\text { The northeast of Tibetan } \\
\text { Plateau (Gannan Prefecture) }\end{array}$ & 380 & EVI & $y=5320.7 x^{1.9776}$ & 0.62 & {$[32]$} \\
\hline \multirow{2}{*}{ V } & $\begin{array}{c}\text { The northwest of } \\
\text { Gannan Prefecture }\end{array}$ & \multirow{2}{*}{62.74} & EVI & $y=1719.1 x^{2.2588}$ & 0.63 & {$[33]$} \\
\cline { 2 - 3 } & (Xiahe County) & & & & & \\
\hline
\end{tabular}

Table 9 shows the results of statistical analysis using the biomass data measured on the ground surface during 2013-2015 in our study area to examine the error of the aforementioned five models. As shown, the Model IV error is the smallest (47.2\%), followed by V, III, II and I. Among the five models, Models I and II based on the entire Tibetan Plateau perform the worse. Although Model I 
achieved the lowest error in the Tibetan Plateau (Table 8), its estimation error of grassland AGB in the study area is highest (71.7\%). Models III, V and IV are built on the regional area (Xiahe and Gannan) of the Tibetan Plateau; their estimation errors are much smaller, around $47 \%$.

Table 9. The estimation error for the grassland AGB based on existing inversion models at the sample plot and the entire study area scales.

\begin{tabular}{cccc}
\hline \multirow{2}{*}{ Model } & Sample Plot Scale & \multicolumn{2}{c}{ Study Area Scale } \\
\cline { 2 - 4 } & REE (\%) & Yield (kg DW/ha) & REE (\%) \\
\hline I & 71.7 & 5748.8 & 68.9 \\
II & 58.6 & 1352.9 & 48.3 \\
III & 47.8 & 1397.8 & 46.2 \\
IV & 47.2 & 1470.8 & 48.0 \\
V & 47.3 & 1551.3 & 44.6 \\
\hline
\end{tabular}

By analyzing the differences in biomass estimation among Models I-V in the study area (Table 8), we can see that the yield per unit area of grassland biomass (1551.3 kg DW/ha) estimated by Model V in Xiahe County is closest to the ground-measured value of the grassland AGB in the experimental area, and its estimation error for yield per unit area is the lowest among the five models (44.6\%). The yield per unit area of grassland AGB estimated by Model I for the experimental area (5748.8 kg $\mathrm{DW} / \mathrm{ha}$ ) is much larger than the ground-measured value, and its estimation error is also the largest $(68.9 \%)$; the error of the yield per unit area estimated by the other three models ranked from small to large as III, IV and II.

Compared with this study, either at the sample plot scale or the regional scale (namely, the study area of Xiahe County), the estimation accuracy of grassland AGB based on $\mathrm{NDVI}_{\mathrm{MOD}}$ is the highest, and its estimation error for the yield of grassland AGB per unit area is the smallest in the experimental area (39.3\%) (Table 7). Although the previous inversion Models I-V can reflect the overall variation trend of grassland biomass, their errors are higher when applied to our study area. The reason is that in large areas (the Tibetan Plateau area or an entire prefecture or county), the types of natural grassland pasture are complicated, the geographical distribution is wide, the spatial heterogeneity is strong and the vegetation index value is subject to influences from many features and factors (e.g., the ecological environment of the grassland). Therefore, the models built based on a large scale, when applied to small local areas (such as this experimental area), would result in large errors and low accuracy, poor stability and large spatial variations. This conclusion is similar to the results of other studies in other areas [16,34-37].

\subsection{Limitations and Prospects of Remote Sensing Monitoring Biomass}

In this study, although the optimum models for the remote sensing monitoring of grassland biomass in the study area are determined, due to the limitations of factors, such as the duration of sampling on the ground (only the growing seasons of the grassland from 2013-2015 were sampled), there is still some error and uncertainty for these inversion models, especially the grassland biomass inversion model based on the MODIS NDVI data. There are clearly two areas that we may improve in the future. One is the NDVI saturation problem, as is clearly seen in Figure 4 when the biomass is larger than $3000 \mathrm{~kg} \mathrm{DW} / \mathrm{ha}$. One way to solve this problem is to use the wide dynamic range vegetation index (WDRVI) [38-40], which was developed mostly to simulate the biomass for crops, usually with very high biomass. It is worthy to introduce WDRVI for the grassland biomass study in the future, especially to explore its sensitivity to the high end of grassland biomass. The other one is the bidirectional reflectance distribution function (BRDF) effects on all remotely-sensed NDVI. As the BRDF effects are already considered in the MODIS NDVI products, our derived NDVI from the Landsat and $\mathrm{HJ}-1 \mathrm{~B}$ are not. Although it is not the intention of this study to evaluate the methods for deriving BRDF from these two satellites, we notice that quite a few studies have already reported their 
methods [41-44]. For example, one study [45] found that there are $0.02-0.06$ differences for Landsat images between regular reflectivity and BRDF, and it is worthy to explore and use BRDF-derived NDVI for modeling purposes in our future efforts.

The area of grassland resources is distributed broadly worldwide (accounting for approximately $40 \%$ of the global land biome) [2], and the variation on the temporal and spatial scales is dramatic [46]. Satellite data using the relatively high resolutions of Landsat MSS, TM and SPOT show relatively high accuracy in the monitoring of grassland AGB over extended periods; however, because of influences from the transit period, frame width and cloud cover, it is difficult to obtain long time series of high-quality images. Although MODIS has relatively low spatial resolution and relatively large estimation error of grassland AGB, it is still particularly suitable for monitoring widely distributed grassland AGB, mostly due to its high temporal resolution (daily) and large spatial coverage $(2330 \mathrm{~km})$. Therefore, it is important to explore new research approaches to grassland AGB monitoring based on MODIS data to improve the accuracy of grassland remote sensing inversion over large regions in the future. These approaches mainly involve the following aspects: (1) enhance the spatial representativeness of ground sampling sites, for example by increasing their number and area and improving the range observed by the ground sampling site and the corresponding spatial matching problem given the size of satellite image pixels; (2) improve the temporal matching between ground sampling sites and remote sensing data, for example by better scheduling the times of field investigations to reduce the time differences between ground surveys and satellite image acquisitions; (3) incorporate new remote sensing observation techniques (e.g., hyperspectral imagery and the UAV remote sensing technique) and strengthen research on the spectral characteristics of the grassland vegetation community and the applications of the narrow band remote sensing vegetation index in monitoring grassland AGB [47,48]; and (4) construct multi-factor grassland AGB estimation models based on statistical analysis and machine learning techniques. These multiple factors include climatic factors (e.g., sunlight, temperature and rainfall), soil factors (e.g., soil nutrients, soil structure and fertility), biological factors (e.g., grassland type, species richness and distribution of malignant weeds) and management factors (e.g., pasture, fencing enclosures and rotational grazing) [49-51]. For example, Li et al. (2013) used neural networks to build an AGB model based on multiple MODIS vegetation indices and showed higher accuracy than a model based on a single index, by decreased RMSE of $433 \mathrm{~kg} / \mathrm{ha}$ and increased $\mathrm{R}^{2}$ of 0.35 [49]. A multi-factor model by Liang et al. (2016) showed decreased RMSE by $14.5 \%$ as compared with the optimum single-factor model [50]. Diouf et al. (2016) studied the semi-arid grassland in the Sahel region and indicated that a combined photosynthetic radiation and meteorological data model had better performance $\left(R^{2}=0.69\right.$ and RMSE $\left.=483 \mathrm{~kg} D W / \mathrm{ha}\right)$ than the single-factor model of photosynthetic radiation or meteorological data $\left(R^{2}=0.63\right.$ and 0.55 and RMSE $=550 \mathrm{~kg}$ DW $/$ ha and $585 \mathrm{~kg}$ DW/ha, respectively) [51].

\section{Conclusions}

In this study, based on MOD13Q1, HJ-1B CCD and Landsat 8 OLI remote sensing data, grassland observation data in the Sangke grassland of Xiahe County during 2013-2015 are combined to construct a grassland AGB estimation model based on different remote sensing data, and the influence of different filtering approaches for MODIS NDVI on the biomass estimation error of alpine meadow grassland is investigated. The simulation errors of several grassland AGB models in the study area are compared and analyzed, and the applicability of the models is evaluated. The following primary conclusions have been reached.

(1) There is a significant difference in the estimation errors of alpine meadow grassland AGB using remote sensing data from the Chinese HJ-1B CCD, Terra MODIS and Landsat 8 OLI. In this study, the grassland AGB optimum inversion model of the experimental area is the exponential model based on $\mathrm{NDVI}_{\mathrm{MOD}}, \mathrm{NDVI}_{\mathrm{OLI}}$ and $\mathrm{NDVI}_{\mathrm{CCD}}$, but different models show considerable differences in the error of grassland AGB inversion. The errors for the estimation of grassland AGB for the optimum models based on $\mathrm{NDVI}_{\mathrm{MOD}}, \mathrm{NDVI}_{\mathrm{CCD}}$ and $\mathrm{NDVI}_{\mathrm{OLI}}$ at the sample plot level are $35.3 \%$, 
$31.6 \%$ and $29.1 \%$, respectively. Their yield per unit area estimations for grassland AGB in the experimental area indicate that the exponential model based on $\mathrm{NDVI}_{\mathrm{OLI}}$ yielded values closest to the ground-measured value; its estimation error for yield per unit area is the smallest (30.7\%). The estimation error for yield per unit area for the experimental area with the optimum AGB inversion model based on $\mathrm{NDVI}_{\mathrm{OLI}}$ decrease by eight and two percentage points, respectively, compared to the optimum inversion models based on $\mathrm{NDVI}_{\mathrm{MOD}}$ and $\mathrm{NDVI}_{\mathrm{CCD}}$.

(2) The filtering and de-noising processing of MOD13Q1 NDVI are key for reducing the AGB inversion error of alpine meadow grassland based on MODIS data. At the sample plot level, the estimation errors of the AGB estimation models based on $\mathrm{NDVI}_{\mathrm{SG}}, \mathrm{NDVI}_{\mathrm{LO}}$ and $\mathrm{NDVI}_{\mathrm{GA}}$ decreased by 1.40, 1.14 and 1.13 percentage points, respectively, compared to the AGB estimation model based on NDVI $_{M O D}$. On the study area scale (161.36 ha), the estimation errors for the yield per unit area of grassland $\mathrm{AGB}$ based on $\mathrm{NDVI}_{\mathrm{SG}}, \mathrm{NDVI}_{\mathrm{LO}}$ and $\mathrm{NDVI}_{\mathrm{GA}}$ decreased by 4.48, 0.95 and 0.22 , respectively, compared to that based on $\mathrm{NDVI}_{\mathrm{MOD}}$.

(3) The feasibility study on previous models (I and II, III and IV and V) developed (on MODIS indices) at broad scales to apply to our small study area suggests that the estimation error of these models is higher than that of the $\mathrm{NDVI}_{\mathrm{MOD}}$ model constructed in this study by $11.9 \%-36.4 \%$ at the sample plot scale and $5.3 \%-29.6 \%$ at the study area scale. Models V, IV and III based on Xiahe County and Gannan Prefecture do not show considerable difference on the estimation error of AGB, ranging from $47.2 \%-47.8 \%$ at the sample plot level and $44.6 \%-48.0 \%$ of the yield per unit area at the study area level. However, Models I and II based on the Tibetan Plateau scale show much larger estimation error, up to $71.7 \%$ and $58.6 \%$, respectively, at the sample plot scale and $68.9 \%$ and $48.3 \%$ of the yield per unit area at the study area scale.

Acknowledgments: This study was supported by the National Natural Science Foundation of China (31672484, 31372367, 41101337 and 41401472), the Project of the Ministry of Agriculture (201203006), the Program for Changjiang Scholars and Innovative Research Team in University (IRT13019) and the Climate Change Special Foundation of China Meteorological Administration (CCSF201603). We also appreciate the editor's and reviewers' constructive suggestions to greatly improve the paper.

Author Contributions: All authors contributed significantly to this manuscript. To be specific, Baoping Meng and Tiangang Liang designed this study. Baoping Meng, Jing Ge, Shuxia Yang, Jinglong Gao, Qisheng Feng, Xia Cui and Xiaodong Huang were responsible for the data processing, analysis and paper writing. Hongjie Xie made valuable revisions and editing of the paper.

Conflicts of Interest: The authors declare no conflict of interest.

\section{References}

1. Adams, J.M.; Faure, H.; Faure-Denard, L.; McGlade, J.M.; Woodward, F.L. Increases in terrestrial carbon storage from the last glacial maximum to the present. Nature 1990, 348, 711-714. [CrossRef]

2. White, R.; Murray, S.; Rohweder, M. Pilote Analysis of Global Ecosystems: Grassland Ecosystems; World Resources Institute: Washington, DC, USA, November 2000; Available online: http:/ / earthtrends.wri.org/text/forestsgrasslands-drylands/map-229.htm.

3. Scurlock, J.M.O.; Hall, D.O. The global carbon sink: A grassland perspective. Glob. Chang. Biol. 1998, 4, 229-233. [CrossRef]

4. Feng, X.M.; Zhao, Y.S. Grazing intensity monitoring in Northern China steppe: Integrating CENTURY model and MODIS data. Ecol. Indic. 2011, 11, 175-182. [CrossRef]

5. Ma, W.H.; Fang, J.Y.; Yang, Y.H.; Mohammat, A. Biomass carbon stocks and their changes in northern China's grasslands during 1982-2006. Sci. China Life Sci. 2010, 53, 841-850. [CrossRef] [PubMed]

6. Lauenroth, W.K.; Hunt, H.W.; Swift, D.M.; Singh, J.S. Estimating aboveground net primary production in grasslands-A simulation approach. Ecol. Model. 1986, 33, 297-314. [CrossRef]

7. Jobbagy, E.G.; Sala, O.E. Controls of Grass and Shrub Aboveground Production in the Patagonian Steppe. Ecol. Appl. 2000, 10, 541-549. [CrossRef]

8. Soussana, J.F.; Loieau, P.; Vjichard, N.; Ceachia, E.; Balesdent, J.; Chevallier, T.; Arrouays, D. Carbon Cycling and Sequestration Opportunities in Temperate Grasslands. Soil Use Manag. 2004, 20, 219-230. [CrossRef] 
9. Hopkins, A. Relevance and functionality of semi-natural grassland in Europe-status quo and future prospective. In Proceedings of the International Workshop of the Salvere, Raumberg-Gumpenstein, Austria, 26-27 May 2009; pp. 9-14.

10. Moreau, S.; Bosseno, R.; Gu, X.F.; Baret, F. Assessing the biomass dynamics of Andean bofedal and totora highprotein wetland grasses from NOAA/AVHRR. Remote Sens. Environ. 2003, 85, 516-529. [CrossRef]

11. Nordberg, M.L.; Evertson, J. Vegetation index differencing and linear regression for change detection in a Swedish mountain range using Landsat TM and ETMt imagery. Land Degrad. Dev. 2004, 16, 139-149. [CrossRef]

12. Ali, I.; Cawkwell, F.; Dwyer, E.; Barrett, B.; Green, S. Satellite remote sensing of grasslands: From observation to management-A review. J. Plant Ecol. 2016, 9, 649-671. [CrossRef]

13. Rouse, J.W.; Haas, R.H.; Schell, J.A.; Deering, D.W. Monitoring vegetation systems in the Great Plains with ERTS. In Proceedings of the Third ERTS-1 Symposium, Washington DC, USA, 10-14 December 1973; Fraden, S.C., Marcanti, E.P., Becker, M.A., Eds.; NASA SP-351: Washington, DC, USA, 1973; pp. 309-317.

14. Tucker, C.J. Red and Photographic Infrared Linear Combinations for Monitoring Vegetation. Remote Sens. Environ. 1979, 8, 127-150. [CrossRef]

15. Tucker, C.J.; Justice, C.O.; Prince, S.D. Monitoring the grasslands of the Sahel 1984-1985. Int. J. Remote Sens. 1986, 7, 1571-1581. [CrossRef]

16. Ullah, S.; Si, Y.; Schlerf, M.; Skidmore, A.K.; Shafique, M.; Iqbal, I.A. Estimation of grassland biomass and nitrogen using MERIS data. Int. J. Appl. Earth Obs. Geoinf. 2012, 1, 196-204. [CrossRef]

17. Li, F.; Zeng, Y.; Li, X.S.; Zhao, Q.J.; Wu, B.F. Remote sensing based monitoring of interannual variations in vegetation activity in China from 1982 to 2009. Sci. China Earth Sci. 2014, 57, 1800-1806. [CrossRef]

18. Yang, F.; Sun, J.L.; Fang, H.L.; Yao, Z.F.; Zhang, J.H.; Zhu, Y.Q.; Song, K.S.; Wang, Z.M.; Hu, M.G. Comparison of different methods for corn LAI estimation over northeastern China. Int. J. Appl. Earth Obs. Geoinf. 2012, $18,462-471$.

19. Xu, B.; Yang, X.; Tao, W.; Qin, Z.H.; Liu, H.Q.; Miao, J.M. Remote sensing monitoring upon the grass production in China. Acta Ecol. Sin. 2007, 27, 405-413. [CrossRef]

20. Li, F.; Zeng, Y.; Luo, J.H.; Ma, R.H.; Wu, B.F. Modeling grassland aboveground biomass using a pure vegetation index. Ecol. Indic. 2016, 62, 279-288. [CrossRef]

21. Yang, Y.H.; Fang, J.Y.; Pan, Y.D.; Ji, C.J. Aboveground biomass in Tibetan grasslands. J. Arid Environ. 2009, 73, 91-95. [CrossRef]

22. Xie, Y.; Sha, Z.Y.; Yu, M.; Bai, Y.F.; Zhang, L. A comparison of two models with Landsat data for estimating above ground grassland biomass in Inner Mongolia, China. Ecol. Model. 2009, 220, 1810-1818. [CrossRef]

23. Chen, J.; Jönsson, P.; Tamura, M.; Gu, Z.H.; Matsushita, B.; Eklundh, L. A simple method for reconstructing a high-quality NDVI time-series data set based on the Savitzky-Golay filter. Remote Sens. Environ. 2004, 91, 332-344. [CrossRef]

24. Dusseux, P.; Hubert-Moy, L.; Corpetti, T.; Vertès, F. Evaluation of SPOT imagery for the estimation of grassland biomass. Int. J. Appl. Earth Obs. Geoinf. 2015, 38, 72-77. [CrossRef]

25. Wang, X.P.; Guo, N.; Zhang, K.; Wang, J. Hyperspectral Remote Sensing Estimation Models of Aboveground Biomass in Gannan Rangelands. Procedia Environ. Sci. 2011, 10, 697-702.

26. Liu, B.K.; Du, Y.E.; Liang, T.G.; Feng, Q.S. Outburst Flooding of the Moraine-Dammed Zhuonai Lake on Tibetan Plateau: Causes and Impacts. IEEE Geosci. Remote Sens. Lett. 2016, 13, 570-574. [CrossRef]

27. Jia, W.X.; Liu, M.; Yang, Y.H.; He, H.L.; Zhu, X.D.; Yang, F.; Yin, C.; Xiang, W.N. Estimation and uncertainty analyses of grassland biomass in Northern China: Comparison of multiple remote sensing data sources and modeling approaches. Ecol. Indic. 2016, 60, 1031-1040. [CrossRef]

28. Irons, J.R.; Dwyer, J.L.; Barsi, J.A. The next Landsat satellite: The Landsat Data Continuity Mission. Remote Sens. Environ. 2012, 122, 11-21. [CrossRef]

29. Geng, L.L.; Ma, M.G.; Wang, X.F.; Yu, W.P.; Jia, S.Z.; Wang, H.B. Comparison of Eight Techniques for Reconstructing Multi-Satellite Sensor Time-Series NDVI Data Sets in the Heihe River Basin, China. Remote Sens. 2014, 6, 2024-2049. [CrossRef]

30. Feng, Q.S.; Gao, X.H.; Huang, X.D.; Yu, H.; Liang, T.G. Remote sensing dynamic monitoring of grass growth in Qinghai-Tibet plateau from 2001 to 2010. J. Lanzhou Univ. 2011, 47, 75-90.

31. Cui, X.; Guo, Z.G.; Liang, T.G.; Shen, Y.Y.; Liu, X.Y.; Liu, Y. Classification management for grassland using MODIS data: A case study in the Gannan region, China. Int. J. Remote Sens. 2012, 33, 3156-3175. [CrossRef] 
32. Wang, Y.; Xia, W.T.; Liang, T.G.; Wang, C. Spatial and temporal dynamic changes of net primary product based on MODIS vegetation index in Gannan grassland. Acta Pratacult. Sin. 2010, 19, 201-210.

33. Bao, H.M. Dynamic Monitoring and Prediction of Aboveground Biomass of Natural Grassland-A Case Study in Xiahe County of Gansu Province. Master's Thesis, Gansu Agricultural University, Lanzhou, China, 2010.

34. Porter, T.F.; Chen, C.C.; Long, J.A.; Lawrence, R.L.; Sowell, B.F. Estimating biomass on CRP pastureland: A comparison of remote sensing techniques. Biomass Energy 2014, 66, 268-274. [CrossRef]

35. Reddersen, B.; Fricke, T.; Wachendorf, M. A multi-sensor approach for predicting biomass of extensively managed Grassland. Comput. Electron. Agric. 2014, 109, 247-260. [CrossRef]

36. Gao, T.; Yang, X.Y.; Jin, Y.X.; Ma, H.L.; Li, J.Y.; Yu, Q.Y.; Zheng, X. Spatio-Temporal Variation in Vegetation Biomass and Its Relationships with Climate Factors in the Xilingol Grasslands, Northern China. PLoS ONE 2013, 8, e83824. [CrossRef] [PubMed]

37. Ahamed, T.; Tian, L.; Zhang, Y.; Ting, K.C. A review of remote sensing methods for biomass feedstock production. Biomass Bioenergy 2011, 35, 2455-2469. [CrossRef]

38. Gitelson, A.A. Wide Dynamic Range Vegetation Index for remote quantification of biophysical characteristics of vegetation. J. Plant Physiol. 2004, 161, 165-173. [CrossRef] [PubMed]

39. Viña, A.; Henebry, G.M.; Gitelson, A.A. Satellite monitoring of vegetation dynamics: Sensitivity enhancement by the wide dynamic range vegetation index. Geophys. Res. Lett. 2004, 31, 373-394. [CrossRef]

40. Viña, A.; Gitelson, A.A. New developments in the remote estimation of the fraction of absorbed photosynthetically active radiation in crops. Geophys. Res. Lett. 2005, 32, 195-221. [CrossRef]

41. Nagol, J.R.; Sexton, J.O.; Kim, D.H.; Anand, A.; Morton, D.; Vermote, E.; Townshend, J.R. Bidirectional effects in Landsat reflectance estimates: Is there a problem to solve? ISPRS J. Photogramm. Remote Sens. 2015, 103, 129-135. [CrossRef]

42. Zhang, H.K.; Roy, D.P. Landsat 5 Thematic Mapper reflectance and NDVI 27-year time series inconsistencies due to satellite orbit change. Remote Sens. Environ. 2016, 186, 217-233. [CrossRef]

43. Gao, F.; Jin, Y.; Schaaf, C.B.; Strahler, A.H. Bidirectional NDVI and atmospherically resistant BRDF inversion for vegetation canopy. IEEE Trans. Geosci. Remote Sens. 2002, 40, 1269-1278.

44. Li, A.; Wang, Q.; Bian, J.; Lei, G. An Improved Physics-Based Model for Topographic Correction of Landsat TM Images. Remote Sens. 2015, 7, 6296-6319. [CrossRef]

45. Roy, D.P.; Zhang, H.K.; Ju, J.; Gomez-Dansd, J.L.; Lewisd, P.E.; Schaaf, C.B.; Sun, Q.; Li, J.; Huang, H.; Kovalskyy, V. A general method to normalize Landsat reflectance data to nadir BRDF adjusted reflectance. Remote Sens. Environ. 2016, 176, 255-271. [CrossRef]

46. Jacques, D.C.; Kergoat, L.; Hiernaux, P.; Mougin, E.; Defourny, P. Monitoring dry vegetation masses in semi-arid areas with MODIS SWIR bands. Remote Sens. Environ. 2014, 153, 40-49. [CrossRef]

47. Liu, M.; Liu, G.H.; Gong, L.; Wang, D.B.; Sun, J. Relationships of biomass with environmental factors in the grassland area of Hulunbuir, China. PLoS ONE 2014, 9, e102344. [CrossRef] [PubMed]

48. Gao, T.; Xu, B.; Yang, X.C.; Jin, Y.X.; Ma, H.L.; Li, J.Y.; Yu, H.D. Using MODIS time series data to estimate aboveground biomass and its spatio-temporal variation in Inner Mongolia's grassland between 2001 and 2011. Int. J. Remote Sens. 2013, 34, 7796-7810. [CrossRef]

49. Li, F.; Jiang, L.; Wang, X.F.; Zhang, X.Q.; Zheng, J.J.; Zhao, Q.J. Estimating grassland aboveground biomass using multitemporal MODIS data in the West Songnen Plain, China. J. Appl. Remote Sens. 2013, 7, 124-131. [CrossRef]

50. Liang, T.G.; Yang, S.X.; Feng, Q.S.; Liu, B.K.; Zhang, R.P.; Huang, X.D.; Xie, H.J. Multi-factor modeling of above-ground biomass in alpine grassland: A case study in the Three-River Headwaters Region, China. Remote Sens. Environ. 2016, 186, 164-172. [CrossRef]

51. Diouf, A.A.; Hiernaux, P.; Brandt, M.; Faye, G.; Djaby, B.; Diop, M.B.; Ndione, J.A.; Tvchon, B. Do Agrometeorological Data Improve Optical Satellite-Based Estimations of the Herbaceous Yield in Sahelian Semi-Arid Ecosystems? Remote Sens. 2016, 8, 668. [CrossRef]

(C) 2017 by the authors. Licensee MDPI, Basel, Switzerland. This article is an open access article distributed under the terms and conditions of the Creative Commons Attribution (CC BY) license (http:/ / creativecommons.org/licenses/by/4.0/). 